\title{
Increasing globalisation in accounting publications
}

\section{Jap Efendi}

Department of Accounting,

Northern Arizona University, USA

Email: Jap.Efendi@nau.edu

\section{Amy F. Holmes}

Department of Accounting,

Trinity University,

San Antonio, TX, USA

Email: aholmes3@trinity.edu

\section{Murphy Smith*}

Department of Accounting, Finance and Business Law,

Texas A\&M University - Corpus Christi,

Corpus Christi, TX, USA

Email: Lawrence.Smith@tamucc.edu

*Corresponding author

\begin{abstract}
The globalisation movement has greatly affected accounting practice but also academic accounting. Authors at the US universities have historically been major contributors to accounting academic research. An increasing percentage of contributors now come from other countries, such as Canada, the UK, Australia, New Zealand and others. This study examines representation of the US and non-US universities in six very highly ranked accounting journals over a 26-year period. Findings show that the average percentages of articles with non-US university representation vary across journals from the lowest, $15.34 \%$, in The Accounting Review (TAR) to the highest, $64.12 \%$, in Accounting, Organizations and Society (AOS). This study reveals that the force of globalisation is affecting accounting research and the publication landscape. These changes could help broaden perspectives and enrich understanding of accounting issues and accounting knowledge, thereby benefiting both scholarship and practice.
\end{abstract}

Keywords: accounting research; accounting journals; globalisation.

Reference to this paper should be made as follows: Efendi, J., Holmes, A.F. and Smith, L.M. (2021) 'Increasing globalisation in accounting publications', Int. J. Critical Accounting, Vol. 12, No. 1, pp.30-53.

Biographical notes: Jap Efendi is an Associate Professor in the Department of Accounting at Northern Arizona University. He specialises in information technology and international accounting research. 
Amy F. Holmes is an Assistant Professor in the Department of Accounting at Trinity University. She worked in public accounting for almost 30 years before retiring to go back to school and obtained her Accounting $\mathrm{PhD}$. She then started here second career as an Accounting Professor. Her specialties include business valuation and governmental/not-for-profit accounting.

L. Murphy Smith is a Professor of Accounting at the Texas A\&M University Corpus Christi. His academic record includes over 200 research articles, books and monographs, academic conference presentations, research grants, and awards for teaching and research. He ranks in the top 1\% of authors on Social Sciences Research Network (SSRN.com) by downloaded articles (over $71,000)$. His work is highly referenced, with over 3,400 citations to his work shown on Google Scholar. His work has been reported in various news media, including National Public Radio, Fortune, USA Today and The Wall Street Journal.

This paper is a revised and expanded version of a paper entitled 'Globalization trend in top accounting publications: an overview of non-us universities representation from 1985 to 2010' presented at American Accounting Association Annual Meeting, Chicago, IL, 10 August 2015.

\section{Introduction}

In general, the world is becoming more internationally interconnected, including academia. Contributing factors include globalisation, advances in technology, and changes in non-US universities. Globalisation brings an increasing connection between businesses and financial markets around the world (Gaspar et al., 2016). There are more businesses with a multinational presence and firms which are cross-listed on multiple exchanges (Saudagaran and Smith, 2013). Around the world, accounting standards are increasingly converging, notably, the widespread acceptance of International Financial Reporting Standards (IFRS) (Axtell et al., 2017; Grossman et al., 2013). Accounting practitioners are faced with rapid globalisation in their field (Meredith and Baxter, 2017). The above are contributing factors leading to a globalisation in the accounting research literature, which is the focus of the current study.

Advances in technology have enabled researchers to be more efficient and has created some specific benefits to accounting academics. Researchers have the world at their fingertips through the internet. Journals are available online and the ease of access brings familiarity and opportunity to the international community. For example, Business Source Complete by EBSCO Publishing is a tool for accessing published literature via the internet and is available through most university libraries. The Social Science Research Network (SSRN e-library) is a resource for scholarly working papers made available for public review prior to acceptance for publication. Researchers also have access to electronic databases such as Wharton Research Data Services (WRDS) provided by The Wharton School at the University of Pennsylvania which enable research from anywhere in the world.

In addition to the globalisation of the business world and advances in technology, there is a change in how universities around the world view top publications. There is a reward system for accounting faculty which not only encourages, but in many cases 
demands publications in top-tier journals for advancement and tenure. There has been an increase in pay parity among countries which increases the attractiveness of the non-US job market. The US minted PhDs are returning to their home countries for job opportunities. In general, there has been a significant increase in international education, such as Chinese students studying at universities in Australia, which is the world's third largest host country for international higher education (Wu and Myhill, 2017). The increase in resources available for research has increased the mobility of accounting faculty who are willing to move overseas either permanently or as a visiting faculty member. Increasing prestige and recognition from publications in top journals encourages more activity and desire to attain a top-tier publication. Publication rates have been used by financial donors as a measure to determine monetary awards for research (Bublitz and Kee, 1984).

This study provides an overview of the US and non-US universities representation in article publication in six very highly ranked accounting journals from 1985-2010. Data from the six accounting journals: Journal of Accounting and Economics (JAE), the Journal of Accounting Research (JAR), The Accounting Review (TAR), Accounting, Organizations and Society (AOS), Contemporary Accounting Research $(C A R)$ and The International Journal of Accounting (TIJA) was collected to examine if country and university participation has changed over the years. While numerous journals publish research on accounting matters, these journals were selected for the analysis because they are either considered top-tier publications and based on their international scope. In terms of quality, each is rated as $\mathrm{A}^{*}$ or $\mathrm{A}$, the two highest journal ratings of the Australian Business Deans Council (ABDC, 2019).

Previous research indicates that top-tier publications include the first five journals listed (Glover et al., 2006; Coyne et al., 2010). TIJA was selected because it is recognised as a top outlet for papers with an international accounting topic (Jones and Roberts, 2005). TIJA was created in 1965 by the University of Illinois with the purpose of developing a better understanding of the international dimension of accounting. Not unexpectedly, results show this journal has the highest percentage of contributions by non-US authors and non-US universities given its purpose. AOS has the highest number of non-US contributions both in number of articles and authorship.

Prior studies on accounting research have focused on journal publication rankings by topical area and methodology (Coyne et al., 2010; Wu et al., 2009; Efendi et al., 2006; Smith, 1994), by university and productivity by authors (Swanson et al., 2007), and by accounting doctoral graduates and publication performance (Brown and Laksmana, 2007). Lukka and Kasanen (1996) looked specifically to answer the question of whether accounting research was a local or global oriented discipline. They found evidence that accounting research was very local in nature in that the author, the journal and the data were from the same country. Only 58 papers from their sample of 1,112 contained a mixture of authors from both the US and non-US universities. This study contributes to the accounting literature by providing evidence that the accounting research is becoming more of a global oriented discipline measured by the change in non-US university participation rates. With the availability of data on a worldwide scale, the participation and the competition for publications in the area of accounting archival research has greatly increased, not only in the USA, but also with international affiliations.

The US dominance and the idea of an 'elite' standing in accounting research literature has been suggested and shown through prior studies (Lukka and Kasanen, 1996; Williams et al., 2006; Qu et al., 2009). The 2009 study by Qu et al. was based solely on 
publications in $C A R$ and shows the Canadian journal is heavily influenced by the USA. Results of the current study confirm that the USA is not only the leading contributor to $C A R$ but also to three of the other five journals in the sample. Findings show that participation by non-US countries and universities increased substantially from the 1985-1999 to the 2000-2010 period, particularly for the Asian countries and universities. Hong Kong ranked 5th overall for the full sample by more than tripling the number of articles published over the sample period. China did not make the top 11 ranking, but it began to participate in publications and held 13th position in $J A E$ and 14th position in $T I J A$ in the later sample period. Korea ranked 6 th in $J A E$, placed in the top ranking for 4 out of the 6 journals and just missed ranking by placing 13th in TIJA.

The current study is important because it confirms that globalisation is reshaping the top accounting publication landscape. Academics benefit from a broader horizon and differing perspectives from others that have come from diverse backgrounds and experiences. An accounting researcher from non-US universities is likely to carry different experiences, different views, different culture, and different institutional backgrounds which bring depth and opportunity for greater understanding of accounting issues for the academic community. Increased globalisation in research shows a concerted effort to improve accounting knowledge and accounting research. The information in this study is also valuable to $\mathrm{PhD}$ students as they evaluate their options on the job market and to research institutions as a tool for attracting faculty and students that are interested in an affiliation with an institution that is active in publishing.

\section{Sample description}

Data was hand collected from electronic publications in Business Source Complete or hard copies of the journals previously defined for the 26 year period from 1985 to 2010 . The data was stored in an ACCESS database and SAS software utilised for the analysis. Table 1 includes the total number of articles in each publication and the percentage of articles that are from non-US affiliations. For the 26 year period, there were a total of 4,649 articles published in the six journals analysed. Information on authors was collected to determine their university affiliation and if any secondary affiliations were listed. The country in which the university exists was added to the database for the purpose of analysing the country contribution to the accounting literature.

\section{Methodology}

All articles for the journals included in the research were categorised by university and author. Two measures were calculated to determine the country representation in the journal articles, percentage of international representation and weighted measure of contribution (adjusting for co-authorship). To determine the contribution by article the authors were assigned a weight for their individual contribution to each paper. For example, if the article included a sole author, the weight assigned to the author was 1.0. If the article included an authorship of two authors, each was given a weight of 0.5 . This method was used to determine the weighted contribution by author and university (Mathieu and McConomy, 2003; Qu et al., 2009). Analysis was conducted to determine the contribution to each journal by rank of country, university and author. 
Table 1 Publications from 1985 to 2010 (see online version for colours)

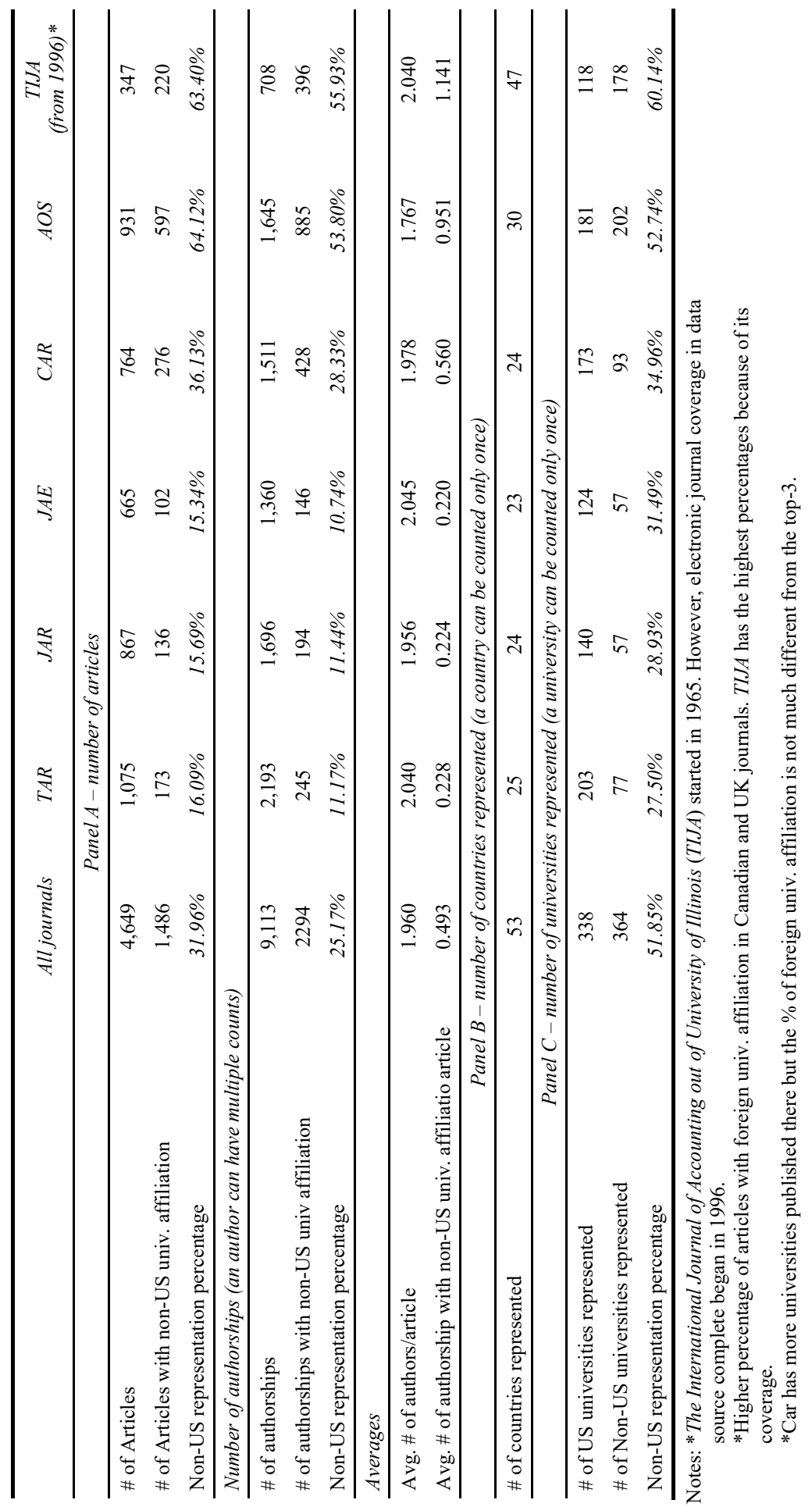


A ranking by country and university was determined for a combined total of all journals in the scope of this project as well as rankings for each separate journal. To evaluate the changes over time, the years were divided into two subgroups consisting of the years 1985 to 1999 and 2000 to 2010 . Please note that the first period contains 15 years and the second period contains 11 years. The two periods allow for analysis of the percentage increase and the ranking in number of articles and authorship. The total number of articles by sub-period has to be interpreted carefully since the number of years is inconsistent in the groupings.

\section{Results}

Table 1 includes an analysis of the total number of articles in each publication and the percentage of articles that have non-US representation. For the full sample period, there was a total of 4,649 articles published in the six journals analysed of which 1,486 had non-US representation shown in Panel A. AOS had the highest non-US representation by articles with non-US university affiliation with a total of 597 articles out of $931(64.12 \%)$ followed by TIJA with 220 articles out of $347(63.40 \%)$. CAR was above the average for all journals with a total of 276 out of $764(36.13 \%)$. JAE was the lowest with 102 out of 665 (15.34\%), which was not much different from TAR and JAR which were 173 out of $1,075(16.09 \%)$ and 136 out of 867 (15.69\%), respectively.

The second measure was number of authorships. The non-US representation by authorships with non-US university affiliation was not limited to a single count per author, each contribution was counted. The journal with the highest non-US representation by author was TIJA with 396 out of $708(55.93 \%)$ followed by AOS with 885 out of $1,645(53.80 \%)$. CAR again was just above the average with a total of 428 out of $1,511(28.33 \%)$. The three US journals had non-US author representation around $11 \%$.

The third measure was the average number of authors per article taking the first measure of number of articles divided by the second measure, number of authorships. For the entire sample period, the average number of authors per article was just above 2 for $T A R, J A E$ and TIJA with the lowest average of 1.767 authors per article for AOS.

The number of countries represented in each article was measured by counting a contributing country only once. Panel B displays the number of countries represented in each journal. The journal with the greatest number of countries represented was TIJA with 47 countries represented, $A O S$ had 30 and the other four journals in the sample were all at 23 to 25 .

The final measure included in Table 1 was the number of universities represented. The count was limited to a single count per university and the results are displayed in Panel C. The full sample included 338 US universities and 364 non-US universities represented for a total representation of $51.85 \%$ for non-US universities. The journal with the highest representation of non-US universities was TIJA with 178 non-US universities and only 118 US universities for a total of $60.14 \%$ for non-US universities. The next highest was $A O S$ with 181 US and 202 non-US for a non-US representation of $52.74 \%$. $A O S$ had the most diverse representation both in the number of total universities represented (a total of 383) and the highest percentage of non-US university representation out of the total sample for all journals: 202 out of the 364 representing $55.49 \%$ of the non-US universities publishing in the sample period. 
Table 2 Publications by periods (by journals)

\begin{tabular}{|c|c|c|}
\hline Panel A: all journals & $1985-1999$ & $2000-2010$ \\
\hline \multicolumn{3}{|l|}{ Number of articles } \\
\hline \# of articles & 2,399 & 2,250 \\
\hline \# of articles with non-US university affiliation & 646 & 840 \\
\hline Non-US representation percentage & $27.93 \%$ & $37.33 \%$ \\
\hline \multicolumn{3}{|c|}{ Number of authorships (an author can have multiple counts) } \\
\hline \# of authorships & 4,344 & 4,769 \\
\hline \# of authorships with non-US univ. affiliation & 899 & 1395 \\
\hline Non-US representation percentage & $20.70 \%$ & $29.25 \%$ \\
\hline Avg. \# of authors / article & 1.811 & 2.120 \\
\hline Avg. \# of author with non-US affiliation / article & 0.375 & 0.620 \\
\hline Panel B: TAR & $1985-1999$ & $2000-2010$ \\
\hline \multicolumn{3}{|l|}{ Number of articles } \\
\hline \# of articles & 570 & 505 \\
\hline$\#$ of articles with non-US university affiliation & 67 & 106 \\
\hline Non-US representation percentage & $11.75 \%$ & $20.99 \%$ \\
\hline \multicolumn{3}{|c|}{ Number of authorships (an author can have multiple counts) } \\
\hline \# of authorships & 1,064 & 1,129 \\
\hline \# of authorships with non-US univ. affiliation & 77 & 168 \\
\hline Non-US representation percentage & $7.24 \%$ & $14.88 \%$ \\
\hline Avg. \# of authors / article & 1.867 & 2.236 \\
\hline Avg. \# of author with non-US affiliation / article & 0.135 & 0.333 \\
\hline Panel C: JAR & $1985-1999$ & $2000-2010$ \\
\hline \multicolumn{3}{|l|}{ Number of articles } \\
\hline \# of articles & 478 & 389 \\
\hline \# of articles with non-US university affiliation & 55 & 81 \\
\hline Non-US representation percentage & $11.51 \%$ & $20.82 \%$ \\
\hline \multicolumn{3}{|c|}{ Number of authorships (an author can have multiple counts) } \\
\hline \# of authorships & 838 & 858 \\
\hline \# of authorships with non-US univ. affiliation & 71 & 123 \\
\hline Non-US representation percentage & $8.47 \%$ & $14.34 \%$ \\
\hline Avg. \# of authors / article & 1.753 & 2.206 \\
\hline Avg. \# of author with non-US affiliation / article & 0.149 & 0.316 \\
\hline Panel D: JAE & $1985-1999$ & $2000-2010$ \\
\hline \multicolumn{3}{|l|}{ Number of articles } \\
\hline \# of articles & 319 & 346 \\
\hline$\#$ of articles with non-US university affiliation & 40 & 62 \\
\hline Non-US representation percentage & $12.54 \%$ & $17.92 \%$ \\
\hline \multicolumn{3}{|c|}{ Number of authorships (an author can have multiple counts) } \\
\hline \# of authorships & 612 & 748 \\
\hline \# of authorships with non-US univ. affiliation & 53 & 93 \\
\hline Non-US representation percentage & $8.66 \%$ & $12.43 \%$ \\
\hline
\end{tabular}


Table 2 Publications by periods (by journals) (continued)

\begin{tabular}{|c|c|c|}
\hline Panel D: JAE & $1985-1999$ & $2000-2010$ \\
\hline \multicolumn{3}{|c|}{ Number of authorships (an author can have multiple counts) } \\
\hline Avg. \# of authors / article & 1.918 & 2.162 \\
\hline Avg. \# of author with non-US affiliation / article & 0.166 & 0.269 \\
\hline Panel E: CAR & $1985-1999$ & $2000-2010$ \\
\hline \multicolumn{3}{|l|}{ Number of articles } \\
\hline \# of articles & 394 & 370 \\
\hline$\#$ of articles with non-US university affiliation & 141 & 135 \\
\hline Non-US representation percentage & $35.79 \%$ & $36.49 \%$ \\
\hline \multicolumn{3}{|c|}{ Number of authorships (an author can have multiple counts) } \\
\hline \# of authorships & 733 & 778 \\
\hline \# of authorships with non-US univ. affiliation & 199 & 229 \\
\hline Non-US representation percentage & $27.15 \%$ & $29.43 \%$ \\
\hline Avg. \# of authors / article & 1.860 & 2.103 \\
\hline Avg. \# of author with non-US affiliation / article & 0.505 & 0.619 \\
\hline Panel F: AOS & $1985-1999$ & $2000-2010$ \\
\hline \multicolumn{3}{|l|}{ Number of articles } \\
\hline \# of articles & 531 & 400 \\
\hline$\#$ of articles with non-US university affiliation & 288 & 291 \\
\hline Non-US representation percentage & $54.24 \%$ & $72.75 \%$ \\
\hline \multicolumn{3}{|c|}{ Number of authorships (an author can have multiple counts) } \\
\hline \# of authorships & 882 & 763 \\
\hline \# of authorships with non-US univ. affiliation & 409 & 476 \\
\hline Non-US representation percentage & $46.37 \%$ & $62.39 \%$ \\
\hline Avg. \# of authors / article & 1.661 & 1.908 \\
\hline Avg. \# of author with non-US affiliation / article & 0.770 & 1.190 \\
\hline Panel G: TIJA & 1985-1999 & $2000-2010$ \\
\hline \multicolumn{3}{|l|}{ Number of articles } \\
\hline \# of articles & 107 & 240 \\
\hline \# of articles with non-US university affiliation & 55 & 165 \\
\hline Non-US representation percentage & $51.40 \%$ & $68.75 \%$ \\
\hline \multicolumn{3}{|c|}{ Number of authorships (an author can have multiple counts) } \\
\hline \# of authorships & 215 & 493 \\
\hline \# of authorships with non-US univ. affiliation & 90 & 306 \\
\hline Non-US representation percentage & $41.86 \%$ & $62.07 \%$ \\
\hline Avg. \# of authors / article & 2.009 & 2.054 \\
\hline Avg. \# of author with non-US affiliation / article & 0.841 & 1.275 \\
\hline
\end{tabular}

An analysis by period proves to be very interesting. The years were divided into two sub-periods, the first period for the years 1985 to 1999 and the later period for the years 2000 to 2010 . Table 2 shows results of the analysis of publications by period including all journals in the sample and also results by each specific journal. The number 
of authorships with non-US representation increased from $20.70 \%$ to $29.25 \%$. The number of authors per article has increased to an average just over 2 .

Figure 1 Non-US representation in accounting academic research, (a) Panel A - non-US representation by number of articles (b) Panel B - non-US representation by number of authorships (see online version for colours)

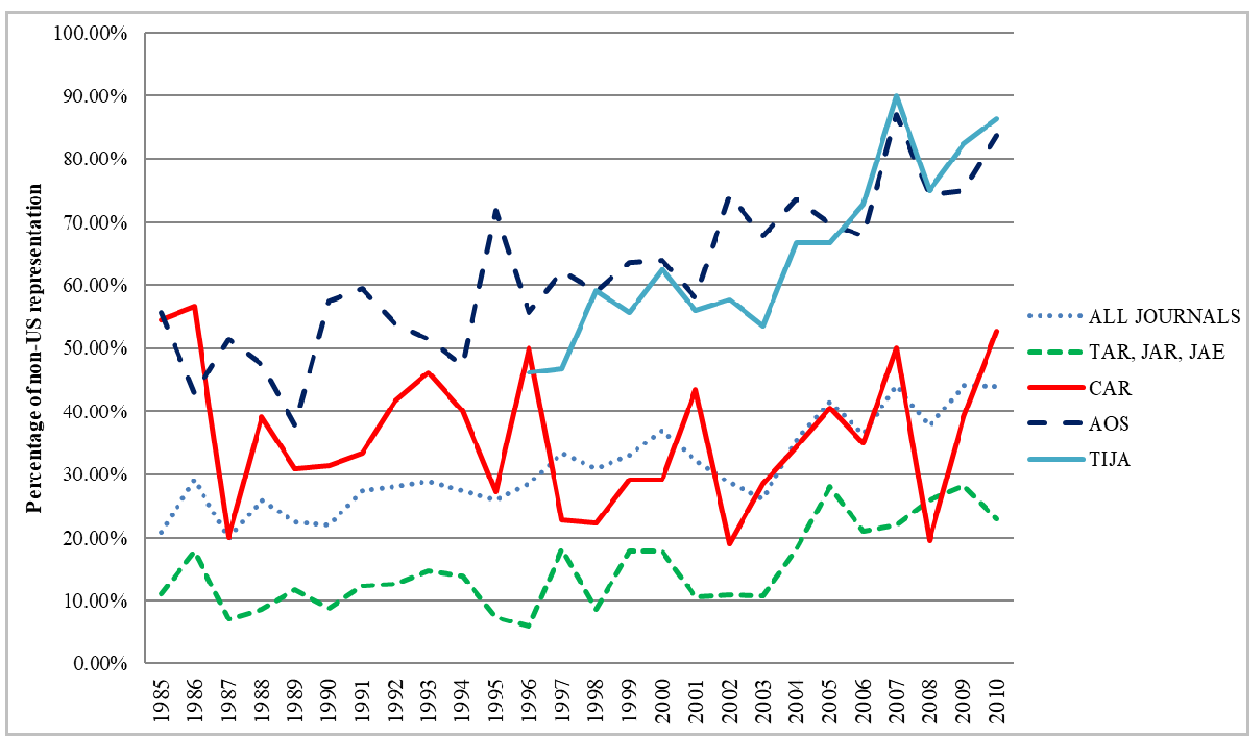

(a)

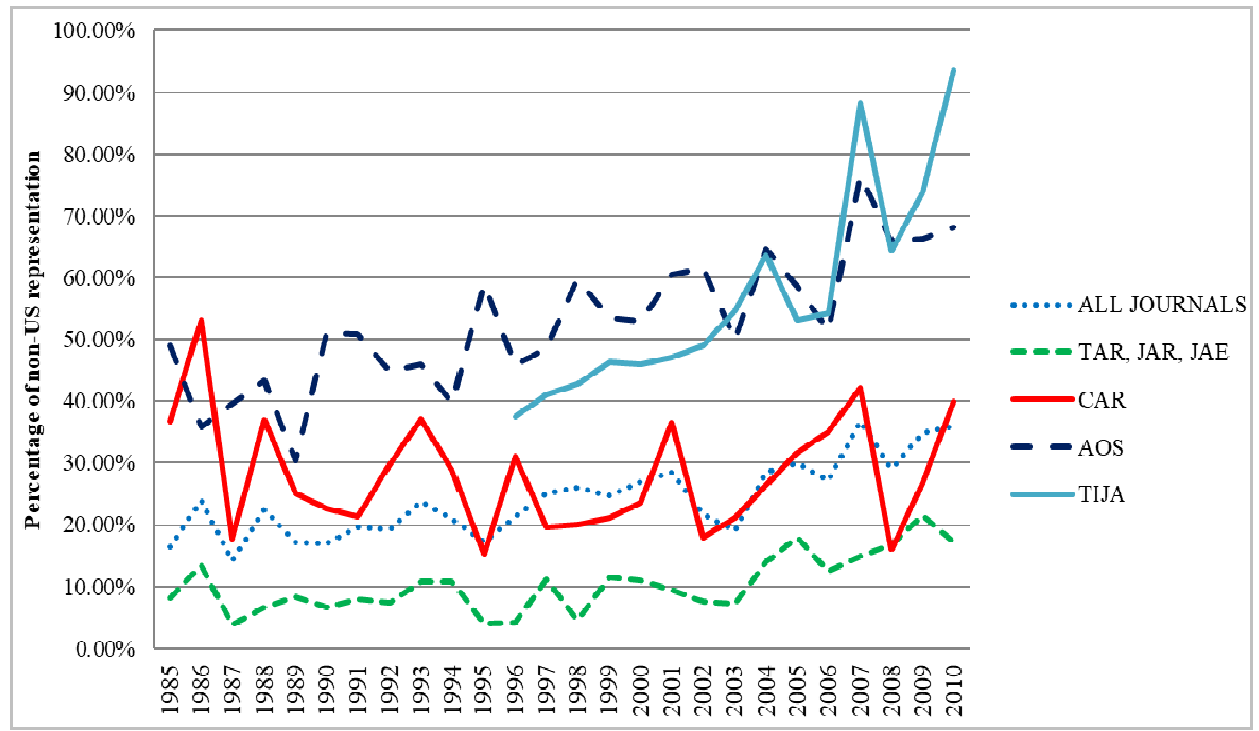

(b)

The non-US representation for percentage of articles with non-US university affiliation almost doubled in TAR and the percentage of authorships with non-US university affiliations doubled from $7.24 \%$ to $14.88 \%$ as shown in Panel B. JAR also had an increase 
almost double for both percentage of articles and percentage of authorships by non-US university affiliations (Panel C). The increase for $J A E$ was close to $50 \%$ (Panel D) and there was not much change in the non-US representation in $C A R$ (Panel E). For $A O S$ and $T I J A$, the percentage of non-US affiliated articles both increased about $34 \%$. The percentage of non-US authors increased about $34 \%$ and $48 \%$, respectively, at $A O S$ and $T I J A$. Figure 1 plots the non-US representation rates for the total sample, CAR, AOS, $T I J A$ and an aggregate for $T A R, J A R$, and $J A E$ over the sample periods. The results by year for non-US representation by percentage of articles are shown in Panel A and authorships in Panel B. As shown on the plots, AOS and TIJA are trending toward greater non-US representation while $T A R, J A R$, and $J A E$ show a slight trend upward in non-US representation. $C A R$ shows a great deal of volatility, but no upward trend.

Table 3 contains the rankings of the top 11 countries represented for the complete sample and also by journal. The rankings are for the countries represented by number of authors for the two sub-periods, 1985-1999 and 2000-2010. The authors are weighted by contribution to an article. For example, if an article has four authors and only one author from Canada, then the weighted count for Canada is 0.25 . For the complete sample of all articles, the top 5 rankings remained unchanged. The total for the USA and Australia was down. The ranking for Hong Kong was the same coming in 5th in both sub-periods, but the number of contributing authors more than tripled. Newcomers to the top 11 rankings for the period 2000-2010 were France, Germany and Belgium, and Spain. Going off the top 11 were Israel, Sweden, New Zealand, and Finland.

The Asian countries show remarkable increases in TAR publications. Hong Kong jumped four places with the number increasing about six times, Singapore jumped five places with the number increasing 9.5 times and Taiwan jumped four places in TA. Hong Kong jumped three places in $J A R$ and Korea jumped into the ranking coming in at 11th place. The UK increased by almost four times which moves its ranking up by two places. Newcomers to the journal also included France and Germany.

The journals from which the sample in which the USA increased in the number of weighted authors were $J A E$ and TIJA. All other journals experienced a decrease for the USA. Hong Kong jumped to second place in $J A E$ with an increase of threefold. The UK jumped two places with an increase of almost six times over the prior period. The USA remains the top listing in $C A R$ with Canada coming in second, both experienced decreases in their numbers. Hong Kong jumped two places to take the third ranking and Taiwan jumped five places which put them in the seventh slot.

An analysis by university contribution was conducted to determine the universities which have the highest contribution rates for the journals in the sample period. The results are given in Table 4 for the full sample and by journal. The pie chart in Figure 2 shows the top 20 non-US universities that were represented in the sample and their respective percentage of the top rankings. The recent top 5 were Hong Kong University of Science as the number one non-US contributor with a weighted contribution of 26.42 articles, followed by University of Alberta with 21 articles, Nanyang Technological University 18.83, Toronto 18.50 and fifth was London School of Economics and Political Science with 18.17 . 
Table 3 Top 11 countries represented by number of authors (weighted) reported by periods*

\begin{tabular}{|c|c|c|c|c|c|}
\hline & All journals & 1985-1999 & & All journals & $2000-2010$ \\
\hline 1 & USA & $1,822.08$ & 1 & USA & $1,507.07$ \\
\hline 2 & Canada & 177.75 & 2 & UK & 147.95 \\
\hline 3 & UK & 139.08 & 3 & Canada & 143.95 \\
\hline 4 & Australia & 96.83 & 4 & Australia & 68.33 \\
\hline 5 & Hong Kong & 20 & 5 & Hong Kong & 63.17 \\
\hline 6 & Israel & 12.33 & 6 & Netherlands & 40 \\
\hline 7 & Sweden & 10.83 & 7 & Singapore & 31.83 \\
\hline 8 & New Zealand & 10.33 & 8 & France & 21.33 \\
\hline 9 & Finland & 9.5 & 9 & Germany & 14.92 \\
\hline 10 & Netherlands & 8.5 & 10 & Belgium & 14.25 \\
\hline \multirow[t]{2}{*}{11} & Singapore & 8.17 & 11 & Spain & 13.83 \\
\hline & $T A R$ & 1985-1999 & & $T A R$ & $2000-2010$ \\
\hline 1 & USA & 517.25 & 1 & USA & 425.55 \\
\hline 2 & Canada & 17.92 & 2 & Canada & 16.92 \\
\hline 3 & Australia & 10.5 & 3 & Hong Kong & 11.92 \\
\hline 4 & Israel & 7 & 4 & Australia & 10.67 \\
\hline 5 & New Zealand & 2.5 & 5 & Singapore & 9.5 \\
\hline 6 & Korea & 2.33 & 6 & Netherlands & 4.42 \\
\hline 7 & Hong Kong & 1.83 & 7 & Taiwan & 2.67 \\
\hline 8 & UK & 2.5 & 8 & UK & 2.67 \\
\hline 9 & France & 1.5 & 9 & Korea & 2.58 \\
\hline 10 & Singapore & 1 & 10 & Denmark & 2.33 \\
\hline \multirow[t]{2}{*}{11} & Taiwan & 0.83 & 11 & Israel & 2.17 \\
\hline & $J A R$ & 1985-1999 & & $J A R$ & $2000-2010$ \\
\hline 1 & USA & 434.17 & 1 & USA & 330.25 \\
\hline 2 & Canada & 12.83 & 2 & Canada & 13.25 \\
\hline 3 & Australia & 10.17 & 3 & UK & 11.33 \\
\hline 4 & Singapore & 3 & 4 & Hong Kong & 8.5 \\
\hline 5 & UK & 3 & 5 & Singapore & 3.92 \\
\hline 6 & New Zealand & 1.5 & 6 & Netherlands & 3.75 \\
\hline 7 & Hong Kong & 1.33 & 7 & France & 3.33 \\
\hline 8 & Denmark & 1 & 8 & Israel & 1.83 \\
\hline 9 & Israel & 1 & 9 & Australia & 1.58 \\
\hline 10 & Netherlands & 1 & 10 & Germany & 1.25 \\
\hline 11 & Spain & 1 & 11 & Korea & 1.25 \\
\hline
\end{tabular}

Note: *TIJA electronic data available through data source complete beginning in 1996. 
Table 3 Top 11 countries represented by number of authors (weighted) reported by periods* (continued)

\begin{tabular}{|c|c|c|c|c|c|}
\hline & $J A E$ & $1985-1999$ & & $J A E$ & $2000-2010$ \\
\hline 1 & USA & 288.67 & 1 & USA & 295.58 \\
\hline 2 & Canada & 9.83 & 2 & Hong Kong & 13.67 \\
\hline 3 & Australia & 5.83 & 3 & Canada & 9.5 \\
\hline 4 & Hong Kong & 4.5 & 4 & UK & 7.33 \\
\hline 5 & New Zealand & 2 & 5 & Australia & 1.83 \\
\hline 6 & UK & 1.17 & 6 & Korea & 1.5 \\
\hline 7 & Austria & 1 & 7 & France & 1.5 \\
\hline 8 & Finland & 1 & 8 & Sweden & 1.17 \\
\hline 9 & Taiwan & 0.83 & 9 & Israel & 1 \\
\hline 10 & Indonesia & 0.5 & 10 & Netherlands & 1 \\
\hline 11 & Israel & 0.5 & 11 & Singapore & 1 \\
\hline & $C A R$ & 1985-1999 & & $C A R$ & $2000-2010$ \\
\hline 1 & USA & 273.33 & 1 & USA & 253.85 \\
\hline 2 & Canada & 93.83 & 2 & Canada & 53.53 \\
\hline 3 & Australia & 6.17 & 3 & Hong Kong & 11.75 \\
\hline 4 & Israel & 3.83 & 4 & Australia & 11.67 \\
\hline 5 & Hong Kong & 3.33 & 5 & Singapore & 9.5 \\
\hline 6 & UK & 3 & 6 & UK & 5.7 \\
\hline 7 & Denmark & 1 & 7 & Taiwan & 5.33 \\
\hline 8 & Netherlands & 1 & 8 & Netherlands & 3.5 \\
\hline 9 & New Zealand & 1 & 9 & New Zealand & 2.33 \\
\hline 10 & Singapore & 0.67 & 10 & Cyprus & 2 \\
\hline 11 & Korea & 0.58 & 11 & Korea & 1.92 \\
\hline & $A O S$ & 1985-1999 & & $A O S$ & $2000-2010$ \\
\hline 1 & USA & 249.67 & 1 & USA & 121.75 \\
\hline 2 & UK & 121.08 & 2 & UK & 101 \\
\hline 3 & Australia & 53.83 & 3 & Canada & 41.17 \\
\hline 4 & Canada & 39.67 & 4 & Australia & 29.92 \\
\hline 5 & Sweden & 10.5 & 5 & Netherlands & 18.5 \\
\hline 6 & Finland & 6.5 & 6 & Sweden & 8.83 \\
\hline 7 & Netherlands & 6.5 & 7 & Denmark & 7.83 \\
\hline 8 & Denmark & 5 & 8 & Belgium & 7.33 \\
\hline 9 & Ireland & 4.5 & 9 & Spain & 7.33 \\
\hline 10 & Singapore & 3.17 & 10 & Germany & 6.17 \\
\hline 11 & Hong Kong & 3 & 11 & France & 5.67 \\
\hline
\end{tabular}

Note: *TIJA electronic data available through data source complete beginning in 1996. 
Table 3 Top 11 countries represented by number of authors (weighted) reported by periods* (continued)

\begin{tabular}{llcllc}
\hline & \multicolumn{1}{c}{ TIJA } & $1985-1999$ & & \multicolumn{1}{c}{ TIJA } & $2000-2010$ \\
\hline 1 & USA & 59 & 1 & USA & 80.08 \\
2 & Australia & 10.33 & 2 & UK & 17.67 \\
3 & UK & 8.33 & 3 & Hong Kong & 13.17 \\
4 & Hong Kong & 6 & 4 & Australia & 12.67 \\
5 & Canada & 3.67 & 5 & Canada & 9.58 \\
6 & Japan & 2 & 6 & France & 9.33 \\
7 & Norway & 2 & 7 & Netherlands & 8.83 \\
8 & Finland & 2 & 8 & Singapore & 6.42 \\
9 & Austria & 1.5 & 9 & Belgium & 5.67 \\
10 & New Zealand & 1.33 & 10 & New Zealand & 4.25 \\
11 & Saudi Arabia & 1.33 & 11 & Germany & 4 \\
\hline
\end{tabular}

Note: *TIJA electronic data available through data source complete beginning in 1996.

The University of Alberta was in the \#1 spot in the initial period and fell to the 2 nd the later period, placing 3rd in $C A R$ with 7.67 articles, 4th in $J A E$ with 1.67 articles, 6th in $J A R$ with 2.42 articles, 7th in $A O S$ with 6.58 articles, and 7th in TAR with 2.67 articles. The big story here is that Nanyang Technological University was not in the top 20 ranking for the initial period and jumped to the third overall rank. Nanyang Technological University had publications in five of the six journals. The university was 2nd in TAR with 6.67 articles, 4th in $C A R$ with 5.83 and 4th in $J A R$ with 2.92 articles, tied for 7 th in $J A E$ with one article and 16th in TJIA with 1.92 articles. Newcomers to the top 20 rankings overall also included Oxford, Cardiff University, Tilburg University, Hong Kong Polytechnic University, Monash University and Laval.

Oxford had the highest number of articles contributed to a single journal in the later period with 14.25 in $A O S$ giving them the number one position in the journal and an overall ranking of 7 th with 15.75 total articles for the sample. Hong Kong University of Science was the number one contributor in TAR, in 2000-2010, with 8.17 articles, the number one contributor in JAE with 8.5 articles, the 5th contributor in JAR with 2.5 articles, the 7th ranking contributor in CAR. Hong Kong University of Science contributed 2.5 articles to TIJA. Toronto was the 2nd highest contributor in JAR with 4.5 articles, and the 2nd highest contributor in $C A R$ with 7.75 articles, and the 3rd ranking contributor in TAR with 4.08 articles.

The London School of Business was ranked 16th in the first sub-period and jumped to 13 th in the later period. They were the number one contributor to $J A R$ with 6.33 articles and 3rd in $J A E$ with three articles. The number one contributor in $C A R$ was Waterloo with 10.33 articles and 9th in $J A R$ with 2.17 articles. London School of Economics and Political Science ranked 5th overall with a total of 18.17 articles, 2nd in $A O S$ with 12.17 articles, 7 th in $J A R$ with 2.33 articles and 20th in $J A E$ with 0.5 articles.

The University of New South Wales ranked 6th overall with a total of 15.75 articles, 4th in TAR with 3.33 articles, 7th in TIJA with 2.67 articles, 8th in CAR with 3.67 articles and 12th in $A O S$ with 5.5 articles. Cardiff University ranked 10th overall with a total of 
13.08 articles, 3rd in AOS with 11.25 articles and tied for 19th in TIJA with 1.5 articles. British Columbia ranked 8th overall with a total of 15.25 articles, 2nd in $J A E$ with six articles, 6th in TAR with 2.92 articles, 8th in $J A R$ with 2.17 articles, and 9th in $C A R$ with 3.17 articles. Manchester Business School ranked 11th overall with a total of 12.92 articles, 2nd in TIJA with 4.25 articles, 4th in $A O S$ with 7.67 articles and tied for 15 th in $J A R$ with one article. Melbourne ranked 17 th overall with a total of 8.92 articles, ranked 5th in TAR with 3.33 articles and 14th in $A O S$ with four articles. HEC France ranked 19th overall with 8.33 total articles, they were number one in TIJA with 4.33 articles and tied for 16th in $A O S$ with 3.33 articles. Laval ranked 20th overall with a ranking of 5th in $C A R$ with 4.83 and 16th in $A O S$ with 3.33. Edinburgh ranked 5th in $A O S$ with 7.33 articles.

Figure 2 Top non-US universities contributing to accounting academic research (see online version for colours)

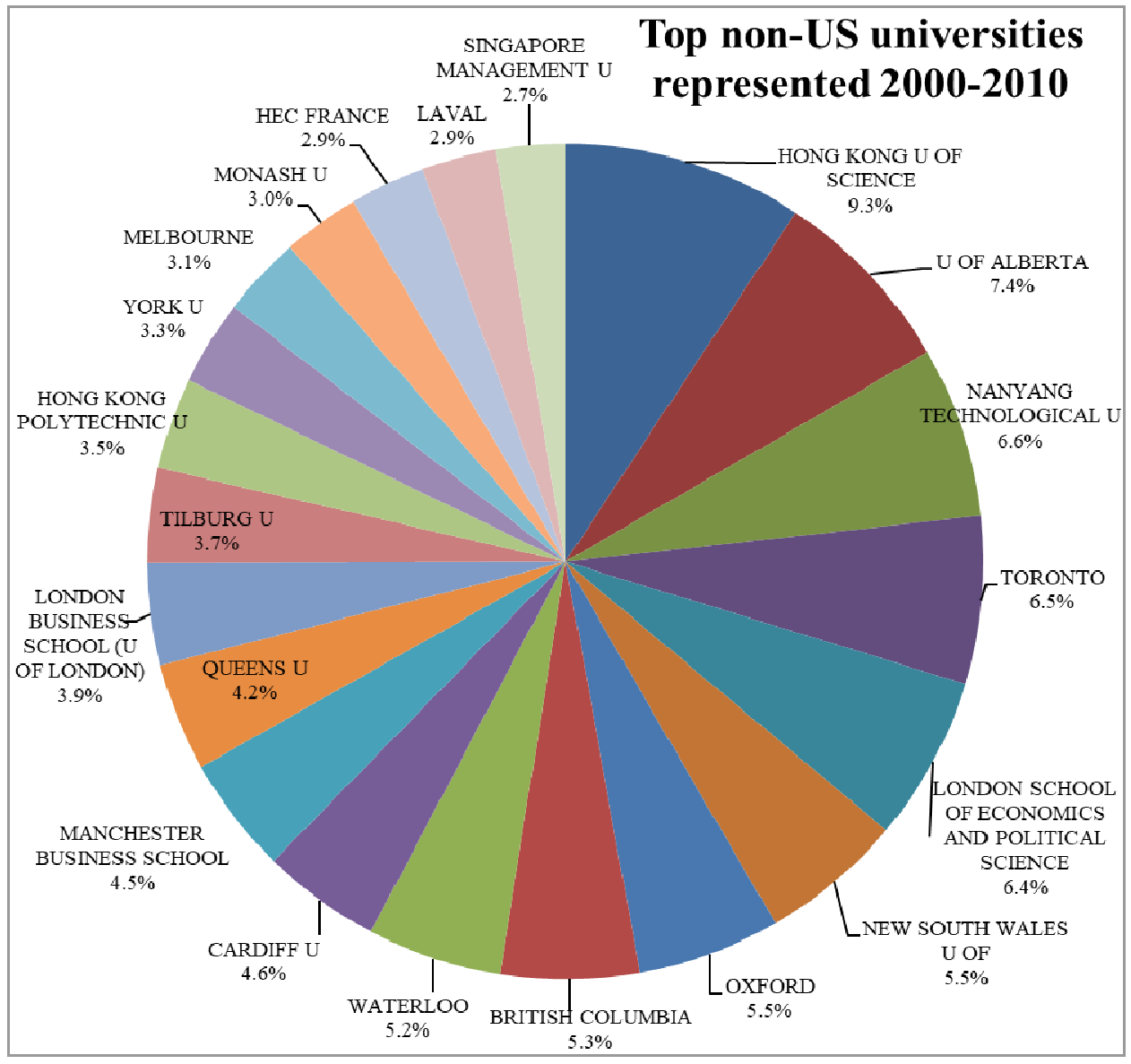

Sung Kyun Kwan University ranked 5th in $J A E$ with 1.5 articles. INSEAD ranked 3rd in JAR with 3.33 and 6th in JAE with 1.17. 
Table 4 Top 20 non-US universities represented by number of articles (weighted) reported by periods 1985-1999 and 2000-2010

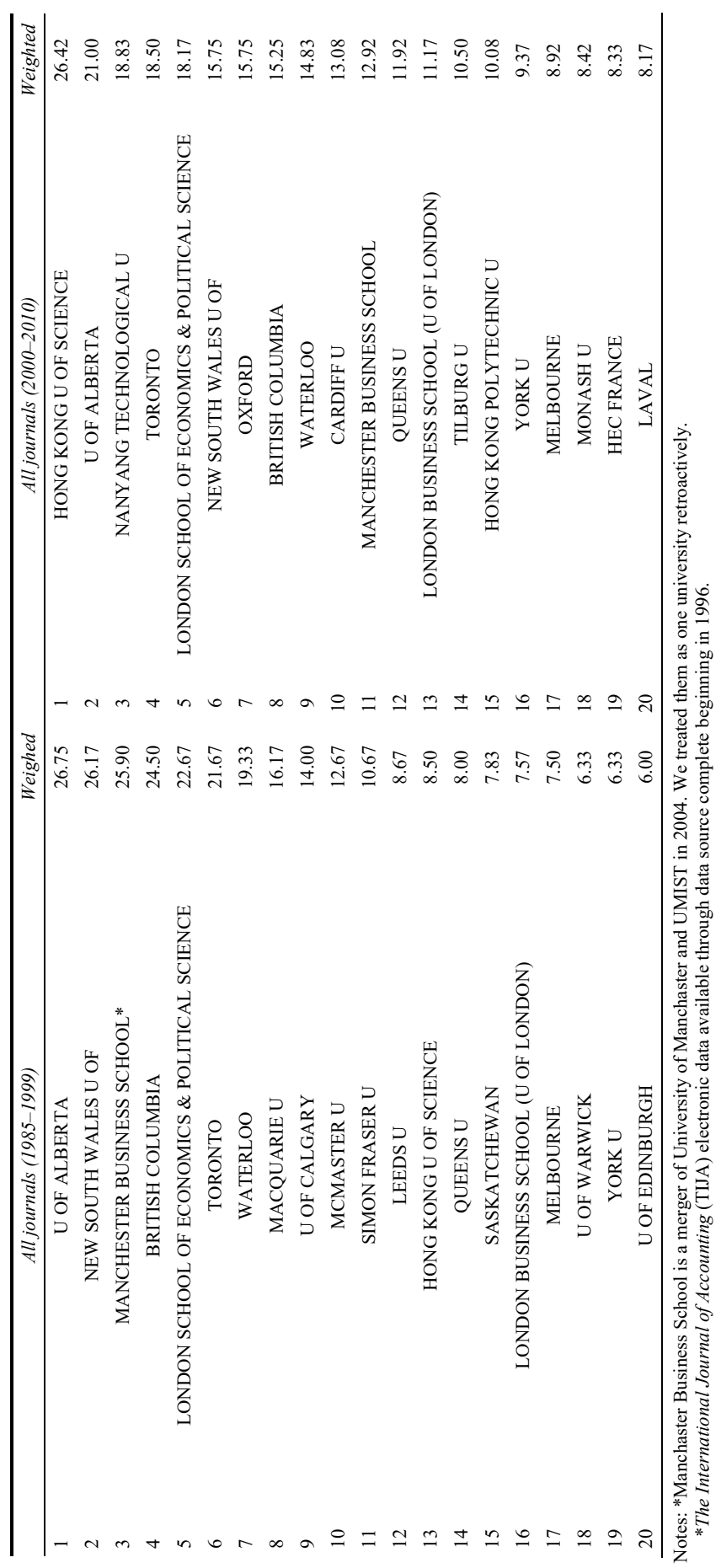


Table 4 Top 20 non-US universities represented by number of articles (weighted) reported by periods 1985-1999 and 2000-2010 (continued)

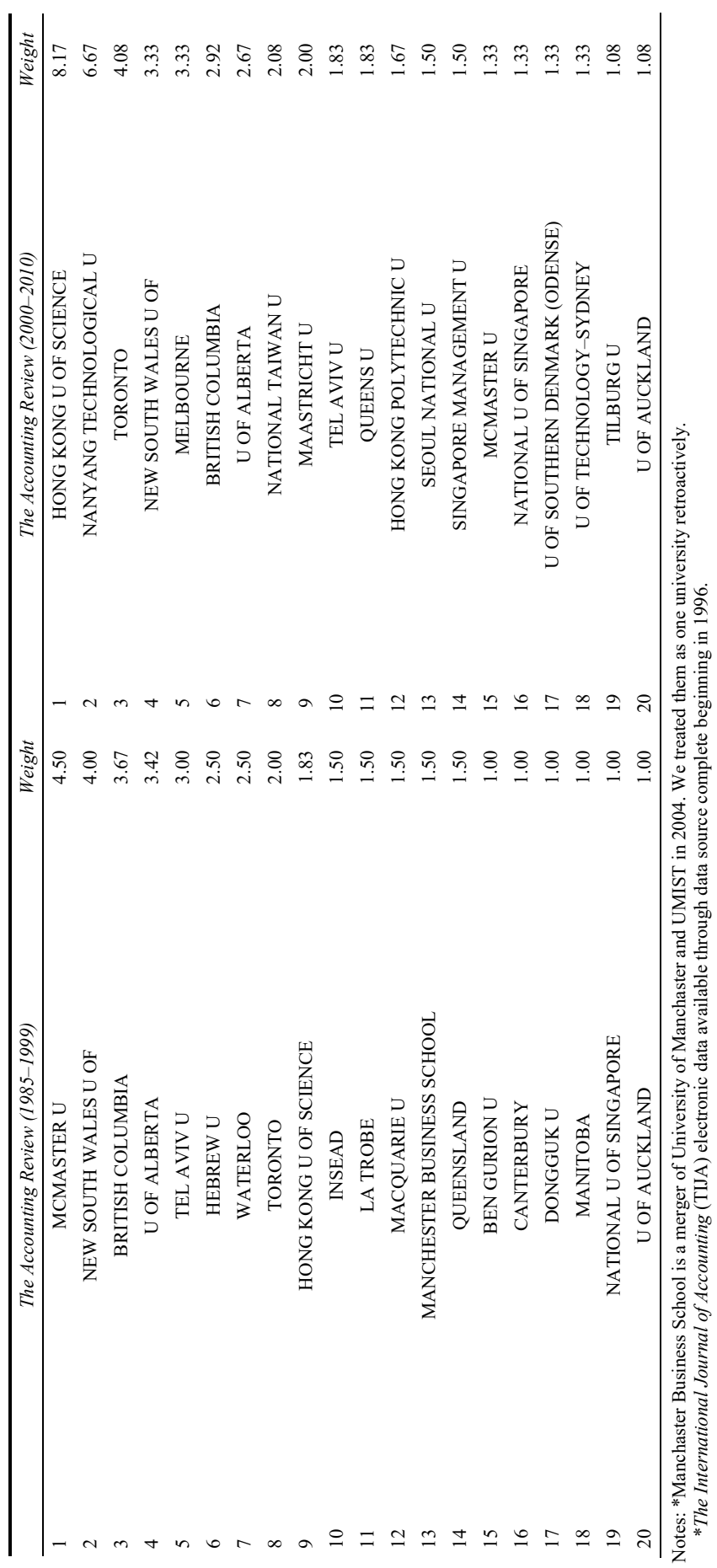


Table 4 Top 20 non-US universities represented by number of articles (weighted) reported by periods 1985-1999 and 2000-2010 (continued)

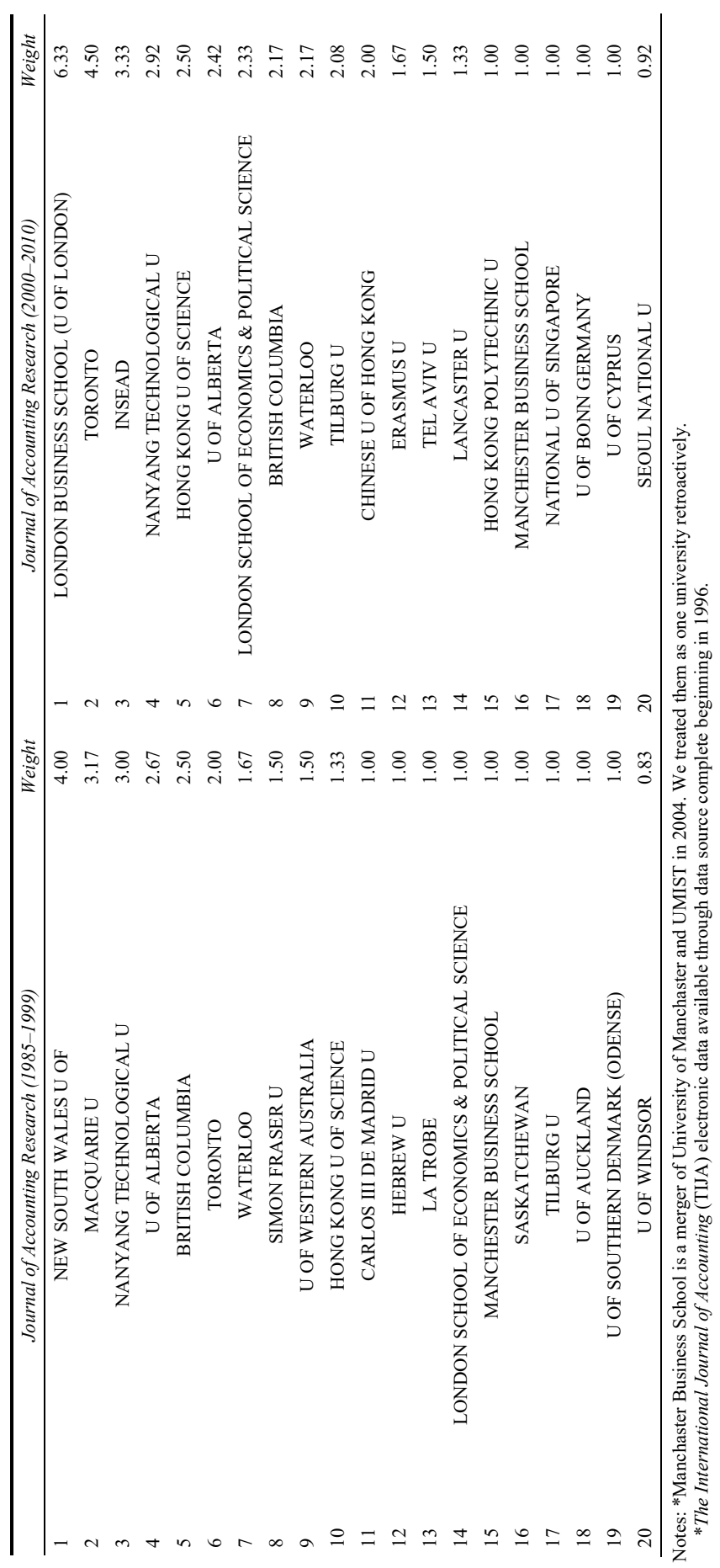


Table 4 Top 20 non-US universities represented by number of articles (weighted) reported by periods 1985-1999 and 2000-2010 (continued)

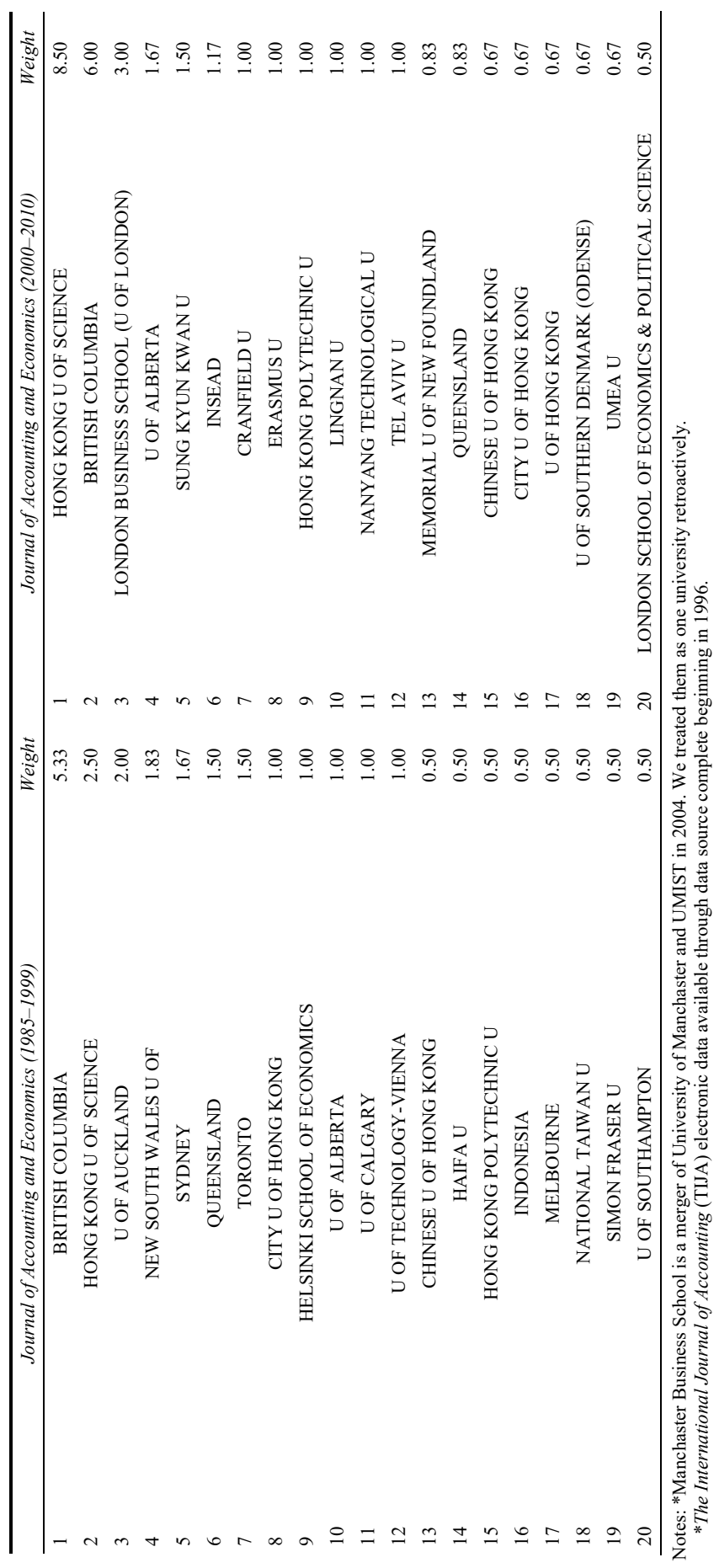


Table 4 Top 20 non-US universities represented by number of articles (weighted) reported by periods 1985-1999 and 2000-2010 (continued)

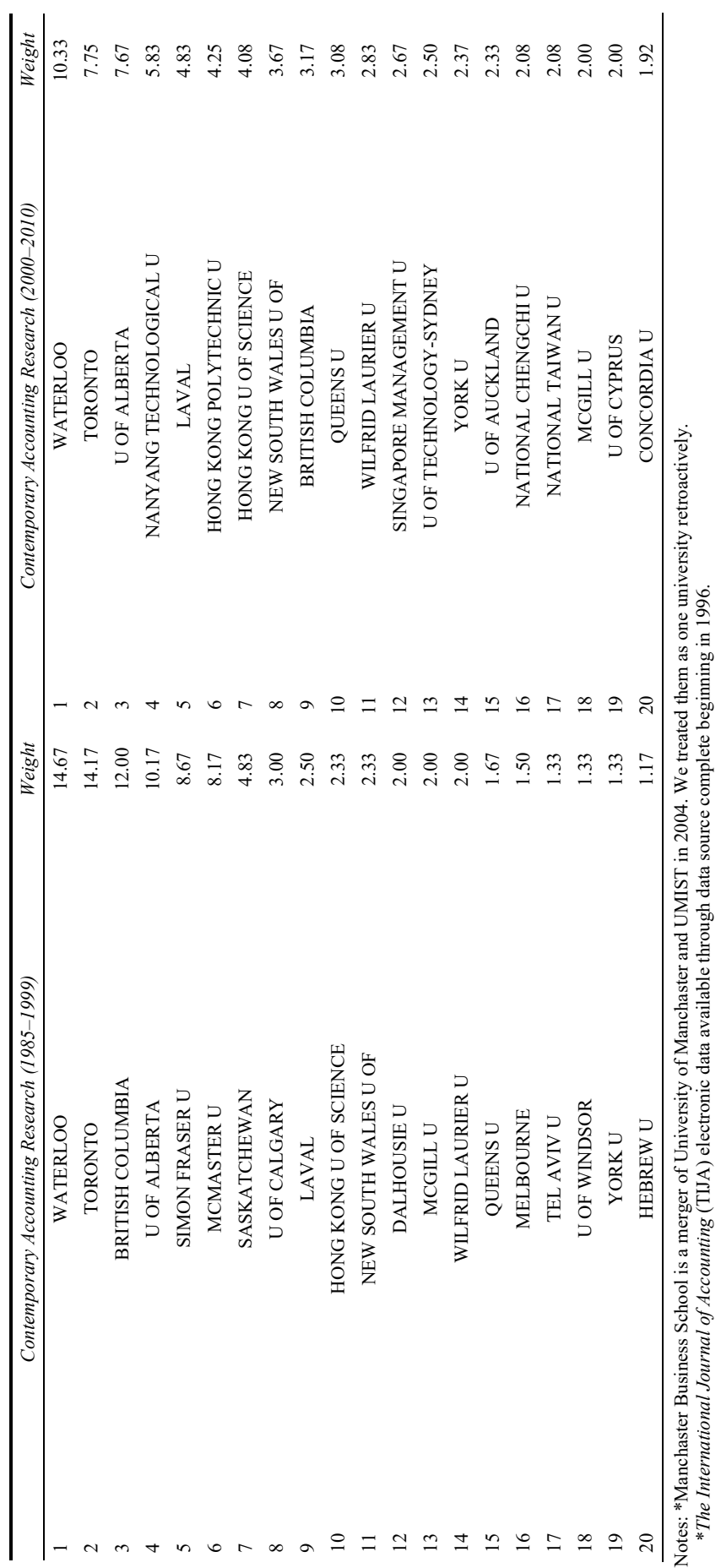


Table 4 Top 20 non-US universities represented by number of articles (weighted) reported by periods 1985-1999 and 2000-2010 (continued)

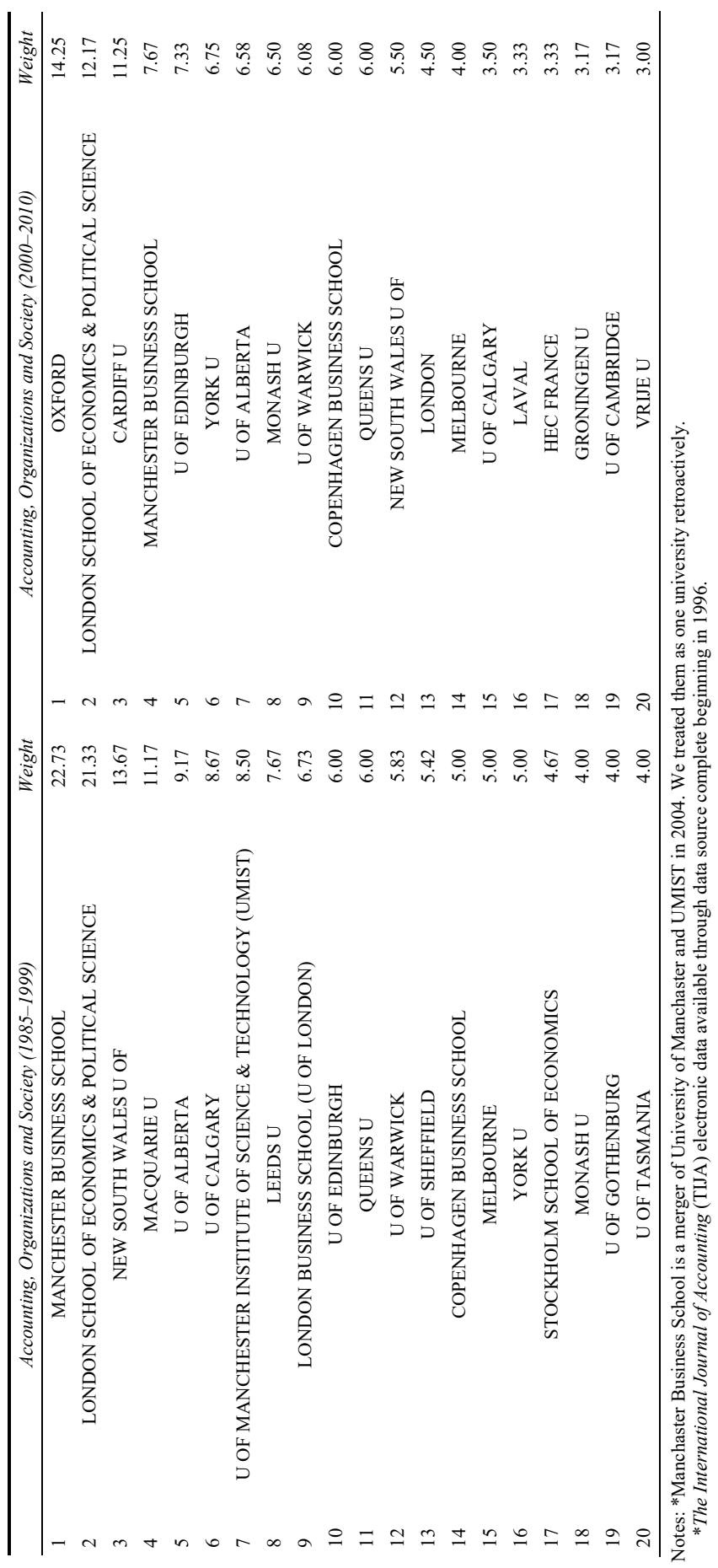


Table 4 Top 20 non-US universities represented by number of articles (weighted) reported by periods 1985-1999 and 2000-2010 (continued)

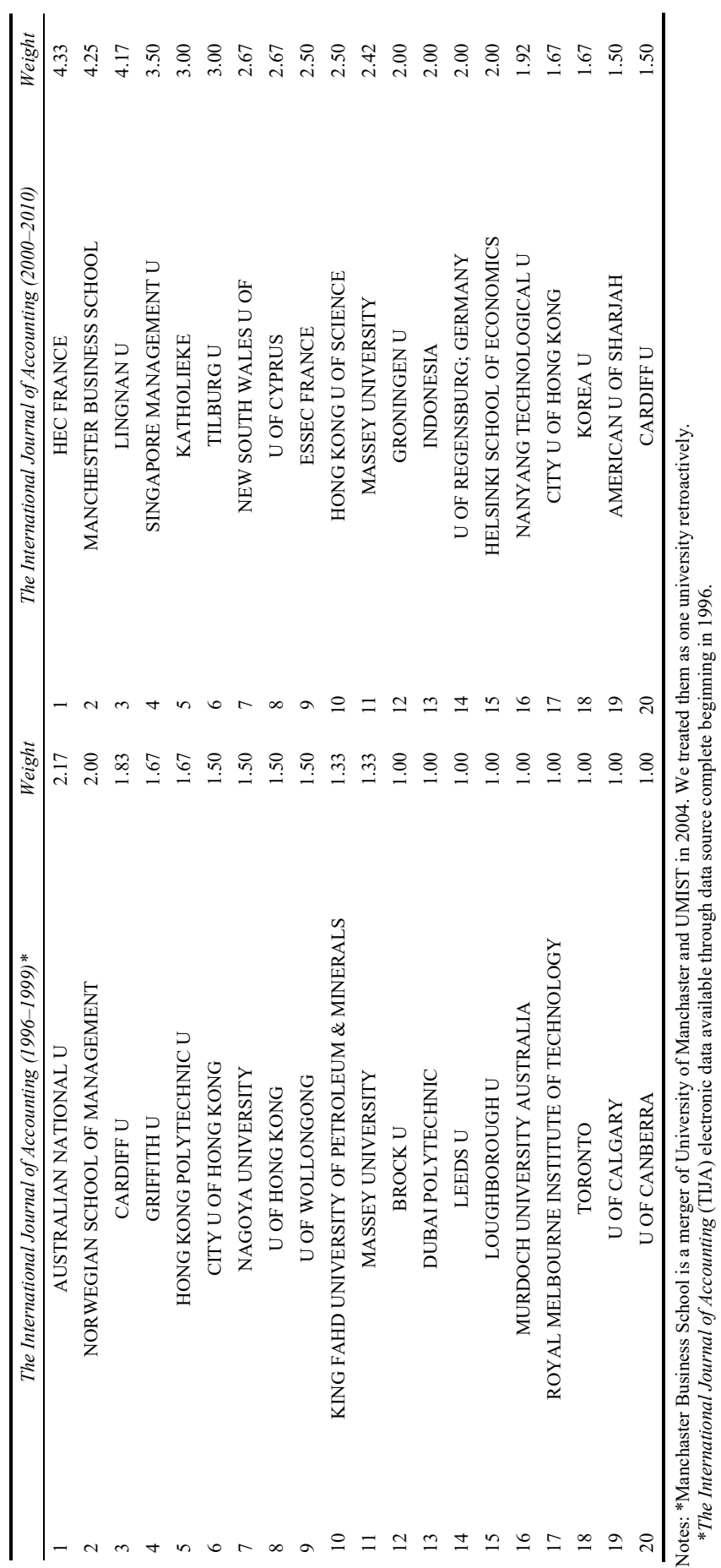


Five of the later period top 10 contributors to TIJA were all newcomers to the rankings in the journals. Lingnan University ranked 3rd with 4.17 articles, Singapore Management University ranked 4th with 3.5 articles, Katholieke tied for 5th with three articles, the University of Cyprus tied for 7th with 2.67 articles and Essec France was tied for 9th with 2.5 articles. Singapore Management barely missed the top 20 overall rankings coming in $21 \mathrm{st}$ with a total of 7.67 articles, they placed 12 th in $C A R$ with 2.67 articles, and tied for 13 th in TAR with 1.5 articles.

The top 5 for each separate journal have been previously mentioned but there are a couple of other universities that warrant a written note of recognition. Hong Kong Polytechnic University was the 15 th overall contributor with 10.08 articles, 6th in CAR with 4.25 articles, and 12th in TAR with 1.67 articles. The university also contributed one article to each JAE and JAR. National Taiwan University ranked 8th in TAR with 2.08 articles and tied for 16th in $C A R$ with 2.08 articles. The full listing of the top 20 non-US university contributors for both periods 1985-1999 and 2000-2010 used for the analysis are given in Table 4.

\section{Conclusions}

The movement to globalise accounting practice, notably International Financial Reporting Standards, has greatly affected accounting practice but also academic accounting. While authors at the US universities have historically been the major contributors to accounting academic research, there are now an increasing percentage of contributors from other countries, such as Canada, the UK, Australia, New Zealand and others. Non-US university representation in journal publications has also increased over the years. There was a remarkable jump of Asian university authors in journal authorship in the later period of the analysis, notably from universities in Hong Kong, Singapore and Taiwan.

This study provides evidence that international participation rates in academic accounting research has increased in recent years. The results suggest that the accounting literature is becoming a more global-oriented discipline. The number of articles with non-US representation almost doubled in TAR and $J A R$. There was a $43 \%$ increase in $J A E$ and just over $30 \%$ increase in $A O S$ and TIJA. The one exception in the sample was $C A R$ which had only a slight increase in non-US representation of less than $1.0 \%$. Although smaller in number of articles, TIJA is the most diverse journal which is not surprising since it is an international journal by designation. $A O S$ has consistently published more articles from diverse author affiliations over the entire sample period. This globalisation of accounting research bodes well for the accounting academic and practice fields, as broader perspectives, that is, a worldwide scope, can potentially benefit both research scholarship and practice.

\section{Limitations and future research}

This study was limited by journal included in the sample: JAE, the JAR, TAR, AOS, CAR and TIJA. Future studies could include other journals. The study was limited to the time period examined. Future studies could include additional time periods, using the current 
study as a benchmark for longitudinal analysis of changes in non-US university representation in journal publications.

\section{References}

ABDC (2019) 2019 Australian Business Deans Council (ABDC) Journal Quality List [online] https://abdc.edu.au/research/abdc-journal-list/ (accessed 19 October 2020).

Axtell, J.M., Smith, L.M. and Tervo, W. (2017) 'The advent of accounting in business governance: from ancient scribes to modern practitioners', International Journal of Business Governance and Ethics, Vol. 12, No. 1, pp.21-46.

Brown, L.D. and Laksmana, I. (2007) 'Accounting Ph.D. program graduates: affiliation performance and publication performance', Review of Quantitative Finance \& Accounting, Vol. 29, No. 3, pp.285-313.

Bublitz, B. and Kee, R. (1984) 'Measures of research productivity', Issues in Accounting Education, Vol. 1, No. 2, pp.39-60.

Coyne, J.G., Summer, S.L., Williams, B. and Wood, D.A. (2010) 'Accounting program research rankings by topical area and methodology', Issues in Accounting Education, Vol. 25, No. 4, pp.631-654.

Efendi, J., Mulig, E.V. and Smith, L.M. (2006) 'Systems research published in major accounting academic and professional journals', Journal of Emerging Technologies in Accounting, Vol. 3, No. 1, pp.117-128.

Gaspar, J., Arreola-Risa, A., Bierman, L., Hise, R., Kolari, J. and Smith, L.M. (2016) Introduction to Global Business, 2nd ed., South-Western Cengage Learning, Mason, OH, USA.

Glover, S.M., Prawitt, D.F. and Wood, D.A. (2006) 'Publication records of faculty promoted at the top 75 accounting research programs', Issues in Accounting Education, Vol. 21, No. 3, pp.195-218.

Grossman, A.M., Smith, L.M. and Tervo, W. (2013) 'Measuring the impact of international financial reporting standards on market performance of publicly traded companies', Advances in Accounting, Vol. 29, No. 2, pp.343-349.

Jones, M.J. and Roberts, R. (2005) 'International publishing patterns: an investigation of leading UK and US accounting and finance journals', Journal of Business Finance \& Accounting, Vol. 32, Nos. 5/6, pp.1107-1140.

Lukka, K. and Kasanen, E. (1996) 'Is accounting a global or a local discipline? Evidence from major research journals', Accounting, Organizations and Society, Vol. 21, Nos. 7/8, pp.775-773.

Mathieu, R. and McConomy, B.J. (2003) 'Productivity in "top-ten" academic accounting journals by researchers at Canadian universities', Canadian Accounting Perspectives, Vol. 2, No. 1, pp.43-76.

Meredith, K. and Baxter, P. (2017) 'Creativity in regional Australian accounting firms', Australasian Journal of Regional Studies, Vol. 23, No. 1, p.120.

Qu, S.Q., Ding, S. and Lukasewich, S.M. (2009) 'Research the American way: the role of US elites in disseminating and legitimizing Canadian academic accounting research', European Accounting Review, Vol. 18, No. 3, pp.515-569.

Saudagaran, S. and Smith, L.M. (2013) International Accounting: A User Perspective, 4th ed., $\mathrm{CCH}$, Chicago.

Smith, L.M. (1994) 'Relative contributions of professional journals to the field of accounting', The Accounting Educators' Journal, Vol. 6, No. 1, pp.1-31, SSRN [online] http://papers.ssrn. com/sol3/papers.cfm?abstract_id=671001.

Swanson, E.P., Wolfe, C.J. and Zardkoohi, A. (2007) 'Concentration in publishing at top-tier business journals: evidence and potential explanations', Contemporary Accounting Research, Vol. 24, No. 4, pp.1255-1289. 
Williams, P.F., Jenkins, J.G. and Ingraham, L. (2006) 'The winnowing away of behavioral accounting research in the US: the process for anointing academic elites', Accounting, Organizations and Society, Vol. 31, No. 8, pp.783-818.

Wu, J., Hao, Q. and Yao, M.Y.M. (2009) 'Rankings of academic journals in accounting, finance, and information systems', International Journal of Accounting and Information Management, Vol. 17, No. 1, pp.66-106.

Wu, Q.A. and Myhill, M. (2017) 'Going off the beaten track: exploring Chinese international students' motivations in selecting a regional Australian university', Australasian Journal of Regional Studies, Vol. 23, No. 1, pp.96-119. 